\title{
Empirical Study of Factors on Teachers' Online Teaching Satisfaction in Higher Education Institutions
}

\author{
Qinling Dai ${ }^{1}$, Ying Guan ${ }^{2}$ and Huajie Shen ${ }^{3, *}$ \\ ${ }^{1}$ Art and Design College, Southwest Forestry University, Kunming, Yunnan 650224, China \\ ${ }^{2}$ College of Sport, Southwest Forestry University, Kunming, Yunnan 650224, China \\ ${ }^{3}$ College of Materials Science and Engineering, Southwest Forestry University, Kunming, Yunnan 650224, China \\ *Corresponding author. Email: $33403352 @ q q . c o m$
}

\begin{abstract}
Online teaching is the main teaching method during the COVID-19 period, and the evaluation and analysis of teachers' teaching satisfaction and the influencing factors are important for the subsequent development of teaching and improvement of methods. In this paper, a survey and research work was conducted with a sample of university teachers who participated in online teaching in China during the COVID-19 period. Firstly, six relevant influencing factors were assumed to be established, and a questionnaire containing 31 questions was set up and conducted according to the assumptions; then, principal component factor analysis was conducted based on the data of the questionnaire to derive the comprehensive factors affecting the satisfaction of online teaching of college teachers; finally, reliability analysis, validity analysis and correlation analysis were conducted on the comprehensive factors. The results show that there is a significant positive correlation between the five comprehensive factors of school policy support, platform, teaching effectiveness, course resources and coursework and online teaching satisfaction of college teachers. The article summarizes and analyzes the research results and puts forward relevant suggestions to provide new ideas for effective online teaching in the post-epidemic era.
\end{abstract}

Keywords: online teaching, satisfaction, higher education

\section{INTRODUCTION}

In response to the impact of the new pneumonia epidemic on the opening of universities and classroom teaching, in spring 2020, the Ministry of Education put forward the requirement of "stopping classes and teaching, stopping classes and learning" [1]. In response, universities and teachers around the world have been using various platforms and resources to actively carry out online teaching activities such as online lectures and online learning. In the post-epidemic era, many scholars began to focus on the investigation and research of online teaching during the new pneumonia epidemic, which mainly includes the following three aspects: first, the study of the teaching effect of a certain course [2], for example, the study of the quality of online teaching of music courses from the perspective of learning environment, learning links, etc.; the effective development of online courses from the perspective of learning atmosphere and teaching order [3,4]; descriptive statistical analysis of online teaching in clinical internship teaching courses in pediatrics [5]; through analyzing the difficulties faced by online teaching of ideological and political theory courses in colleges and universities, and putting forward relevant strategies to solve the dilemma [6]. The second is to study the online learning recognition of college students through a survey of online teaching during the COVID-19 period
$[7,8]$. The third is a study of online teaching platforms and teaching tools in secondary and elementary school [9]. As for higher education institutions, it remains to be studied in depth how teachers teach online and what factors affect the satisfaction of online teaching. In view of this, this paper investigates the influencing factors affecting the teaching satisfaction of higher education teachers based on principal component factor analysis from multiple dimensions such as school policies, teaching effectiveness, course resources, coursework, teachers' teaching and online platforms, and puts forward relevant suggestions based on the findings to provide an empirical reference for online teaching in the post-epidemic era.

\section{DESIGN OF RESEARCH}

\subsection{Framework of Research}

The research framework for studying the influencing factors of online teaching satisfaction of university teachers consists of three main parts.

1) Design of questionnaire items. At this stage, six research factors were initially formulated according to the experts' suggestions, and the corresponding question items were designed. The whole questionnaire consisted of three parts: the teacher background characteristics part, the 
independent variable factor part, and the dependent variable factor part.

2) Data statistics and result analysis. This included statistical analysis of the background information of the sample, exploratory factor analysis of the influencing factors, descriptive analysis, reliability analysis, and validity analysis of the variables, and correlation analysis of the factor variables. The statistical analysis of background information involved the mean, standard deviation and valid sample of the sample background to examine the overall situation of the statistical sample; the exploratory factor analysis analyzed the self-made questionnaire used in the study to grasp the objective influencing factors of online teaching satisfaction of college teachers; the purpose of descriptive analysis, reliability analysis and validity analysis was to study the influencing factors derived from the exploratory factor analysis in the previous stage The overall attitude situation, while examining whether the sample data obtained in the previous stage were true and reliable, and whether the question items were accurate and valid; correlation analysis of variables, to study the interrelationship between variables, i.e. whether there is a correlation between online teaching satisfaction of college teachers and the influencing factors, and the closeness of the relationship.

3 ) Conclusion and recommendation. This stage analyzes the research results and puts forward relevant suggestions for online teaching.

\subsection{Design of the questionnaire}

This study was conducted with teachers who participated in online teaching during the COVID-19 period. Based on interviews and questionnaires from five professionals with educational backgrounds, the hypothesis of this study that six factors namely platform and network, course resources, assigning course work, teachers' teaching style, school policy support, and teaching effectiveness have an effect on teachers' satisfaction with online teaching holds. According to the hypothesis, the 31 core questions of the questionnaire were designed based on these six factors, except for the satisfaction-related questions and the sample background information-related questions, and were distributed through the "Questionnaire Star" platform.

\section{STATISTICAL RESULTS AND ANALYSIS OF DATA}

\subsection{Statistical analysis of background information of the samples}

The basic background characteristics of the sample included five questions on faculty gender, age, title, discipline, and course type of the online course, and the statistical results of these five questions were plotted separately as shown in Table 1 .

Table 1 Sample background information statistics

\begin{tabular}{|c|c|c|c|c|c|}
\hline & Gender & Age & Title & $\begin{array}{c}\text { Course } \\
\text { type }\end{array}$ & Discipline \\
\hline Mean value & 1.6064 & 2.0957 & 2.7660 & 1.8191 & 2.3298 \\
\hline $\begin{array}{c}\text { Median } \\
\text { value }\end{array}$ & 2.0000 & 2.0000 & 3.0000 & 2.0000 & 3.0000 \\
\hline $\begin{array}{c}\text { Standard } \\
\text { deviation }\end{array}$ & .49117 & .67313 & .78186 & .38696 & 1.12056 \\
\hline
\end{tabular}

The official questionnaire was sent out on March 14, 2020 and collected on the $21 \mathrm{st}$, the number of valid samples was 94, and the effective rate of the questionnaire was $97.9 \%$ after removing 2 missing and incomplete samples. Through the statistics of the background information of the samples, we found that the types of online courses of the samples were mainly concentrated in professional courses, accounting for $81.9 \%$ of the total number of samples; the disciplines were mainly concentrated in humanities and social sciences and engineering, accounting for $37.2 \%$ and $42.6 \%$ of the total number of samples, respectively; the titles were mainly concentrated in associate titles, accounting for $46.8 \%$ of the total number of samples; the age groups were mainly concentrated in $36-45$ years old, accounting for $54.3 \%$ of the total sample; the majority of the sample is female, accounting for $60.6 \%$ of the total sample.

\subsection{Exploratory analysis of influencing factors}

The data of the 31 questionnaire items involved in the influence factors were refined by factor concentration using exploratory factor analysis. Specifically, the impact factors were extracted using principal component analysis and rotated using the maximum variance method.

\subsubsection{Initial exploratory factor analysis}

According to the principle of factor extraction with initial characteristic root greater than 1 , seven factors were obtained, and the cumulative variance contributions of these seven factors were $16.64 \%, 31.97 \%, 44.10 \%$, $56.21 \%, 63.21 \%, 67.92 \%$, and $72.52 \%$, respectively. Simultaneous KMO and Bartlett's sphericity tests were performed, as shown in Table 2. the value of KMO was 0.782, which was greater than 0.6, while Bartlett's sphericity test corresponded to a p-value of 0.000 , which was less than 0.05. passing the sphericity test indicated that the prior hypothesis of this study was valid and suitable for exploratory factor analysis. Since the question item with the absolute value of the factor loading coefficient less than 0.4 is the number of online courses, it should be deleted, 
while the number of factors is set to 6 , and the exploratory factor analysis is continued.

\subsubsection{Secondary exploratory factor analysis}

The KMO and Bartlett's spherical test was first performed. the value of KMO was 0.801 , which was greater than 0.6 , and the corresponding p-value of Bartlett's spherical test was 0.000 , which was less than 0.05 , and passed the spherical test. According to the extraction principle of setting the number of six factors, the cumulative variance contribution of the six factors were obtained as $16.93 \%$, $33.13 \%, 46.42 \%, 59.08 \%, 66.92 \%$, and $71.99 \%$, as shown in Table 2 above, and the total variance explained was $70.415 \%$, which was greater than $60 \%$, indicating that the extracted six factors could explain $70.415 \%$ of the entire questionnaire amount of information, and the overall exploratory factor results are good.

Table 2 Total variance explained

\begin{tabular}{|c|c|c|c|c|c|c|c|c|c|}
\hline \multirow{2}{*}{ Component } & \multicolumn{3}{|c|}{ Initial Eigenvalues } & \multicolumn{3}{c|}{ Extract Sum-of-Squares } & \multicolumn{3}{c|}{ Load Rotate Sum-of-Squares Load } \\
\cline { 2 - 10 } & Total & Variance \% & Cumulative \% & Total & Variance \% & Cumulative \% & Total & Variance \% & Cumulative \% \\
\hline 1 & 6.948 & 25.735 & 25.735 & 6.948 & 25.735 & 25.735 & 4.572 & 16.934 & 16.934 \\
\hline 2 & 5.520 & 20.443 & 46.178 & 5.520 & 20.443 & 46.178 & 4.373 & 16.196 & 33.130 \\
\hline 3 & 2.411 & 8.930 & 55.108 & 2.411 & 8.930 & 55.108 & 3.587 & 13.287 & 46.417 \\
\hline 4 & 1.784 & 6.609 & 61.717 & 1.784 & 6.609 & 61.717 & 3.418 & 12.661 & 59.078 \\
\hline 5 & 1.507 & 5.582 & 67.299 & 1.507 & 5.582 & 67.299 & 2.134 & 7.905 & 66.982 \\
\hline 6 & 1.268 & 4.695 & 71.994 & 1.268 & 4.695 & 71.994 & 1.353 & 5.012 & 71.994 \\
\hline 7 & .970 & 3.591 & 75.585 & & & & & & \\
\hline$\vdots$ & $\vdots$ & $\vdots$ & & & & & & & \\
\hline
\end{tabular}

Note: Extraction method: principal component analysis

\subsubsection{Determination of composite factors}

In order to determine the correspondence between the factors and the question items, the variance needs to be spatially rotated in order to understand which question items are distributed under the same factor. According to the maximum variance rotation method, the result matrix of factor analysis after rotation is obtained. In this matrix, the distribution of individual question items varied from the correspondence between the initial hypothetical factors, for example, the composite factor 1 consisted of six question items, such as school building, school uniform deployment, school uniform standards, school enhanced services, training, and supervision, and the absolute values of the question item factor loading coefficients were 0.870 , $0.864,0.859,0.798,0.797,0.772$ The absolute values of the loading coefficients of the factors were $0.898,0.889$, $0.889,0.885$ and 0.858 respectively; the composite factor 2 consisted of five items, namely, good platform performance, easy platform operation, platform service, platform function and platform system stability, and the absolute values of the loading coefficients of the factors were $0.898,0.889,0.889,0.885$ and 0.858 respectively; the composite factor 3 consisted of five items, namely, enhancing teaching skills, teacher-student interaction, improving curriculum advancement, teaching informatization and mainstream teaching. The absolute values of the loading coefficients of the subject factors were $0.839,0.812,0.780,0.717$, and 0.546 , respectively; the composite factor 4 consisted of five items: richness of resources, variety of resources, speed of updating resources, usefulness of resources, and network situation, and the absolute values of the loading coefficients of the subject factors were $0.853,0.822,0.782,0.762$, and 0.546 , respectively. The absolute values of the loading coefficients of the composite factor are $0.853,0.822,0.782$, $0.762,0.502$; the absolute values of the loading coefficients of the composite factor 5 are $0.803,0.783,0.554$; the absolute values of the loading coefficients of the composite factor 6 are $0.616,0.607,0.507,0.502$; the absolute values of the loading coefficients of the composite factor 6 are $0.616,0.607,0.607,0.607,0.502 .0 .616,0.607$, and 0.542 , respectively.

From the corresponding numerical relationships between the above factors and the loading coefficients of the topic factors, it can be concluded that the comprehensive factor 1 consists of six topics, including school establishment, school unified deployment, school unified standard, school enhanced service, training, and supervision, etc. Combining the contents of the topics, the comprehensive factor 1 is named as the school policy support factor; similarly, the comprehensive factors $2 \sim 6$ are named as the 
factors of platform, teaching effectiveness, course resources, coursework, and teachers' teaching style, respectively.

\subsection{Reliability, validity and correlation analysis of the composite factors}

Reliability, which refers to the degree of trustworthiness of the measurement, was analyzed to focus on whether the quality of reliability would be substandard due to the unreasonable design of the scale questions during the study[10], i.e., whether the study data are reliable, which is usually measured by Cronbach's alpha coefficient. Separate reliability analyses were conducted on online teaching satisfaction and the six 9composite factors (school policy support, platform, teaching effectiveness, course resources, coursework, and teacher teaching) obtained from exploratory factor analysis, and the statistical results showed that the Cronbach's alpha coefficient was 0.816, which was greater than 0.4 , indicating that the research data had high reliability.

Two statistical methods are generally used for validity analysis, namely validating factor analysis and exploratory factor analysis, and exploratory factor analysis was used in this paper. The process of validation using exploratory factor analysis is the same as the previous process of composite factor extraction, and from the statistical results of exploratory factors mentioned above, it can be seen that exploratory factor analysis passed Bartlett's spherical test and finally obtained six composite factors; and there is basically a good correspondence between these six composite factors and the question items; the cumulative variance after factor rotation is The cumulative variance after factor rotation was $71.994 \%$, so the composite indicates that the information to be measured The sample data obtained through the questionnaire items are true and reliable, and the questions are accurate and valid with good structural validity.

Correlation analysis is a quantitative analysis method that effectively reveals whether there is a correlation between objective things[11], and the strength of the correlation between two two variables is precisely measured by the correlation coefficient. In this study, By calculating Spearman's correlation coefficient to analyze the strength of correlation between them, it can be concluded from the data that among the six integrated factors of school policy support, platform, teaching effectiveness, curriculum resources, coursework, and teachers' teaching, except for the factor of teachers' teaching, the five factors of school policy support, platform, teaching effectiveness, curriculum resources, and coursework all showed a This indicates that there is a significant positive relationship between school policy support, platform, teaching effectiveness, course resources, and coursework, respectively, and satisfaction.

\section{CONCLUSION AND RECOMMENDATIONS}

The above findings show that there is a significant positive relationship between each of the five factors: school policy support, platform, course resources, coursework, and teaching effectiveness and satisfaction, with the strongest significant relationship between teaching effectiveness, coursework, and platform factors and teachers' online teaching satisfaction. The reasons may be that the teaching effectiveness in terms of teachers' improved information technology, improved teaching skills, and enhanced teacher-student interaction by online methods have made teachers' online teaching familiar, calm, and even preferable from their initial unfamiliarity and nervousness; the convenience of sending pre-reading materials online, sending in-class quizzes during the course, sending postclass assignments, and the ease of the platform in the process of teachers' online teaching In the process of online teaching, teachers' satisfaction with online teaching is enhanced to a great extent by the convenience of sending pre-study materials online, sending in-class quizzes during the course, sending after-class homework, and the ease of operation and functionality of the platform. At the same time, the richness, diversification and speed of updating the platform resources and the support of school policies, such as the unified deployment of the school, the provision of fine services, the formulation of teaching implementation standards, the development of teaching evaluation system, the training and the implementation of teaching supervision, also play a great role in the satisfaction of online teaching. There is no significant correlation between the factor of teachers' teaching style and teachers' satisfaction with online teaching, which may be due to the fact that this factor only includes the number of online teaching courses, the way of teaching organization and the degree of improvement of teaching programs. According to the data, it is possible that whether there is one or two or even more online courses has no direct effect on teachers' online course satisfaction; whether the same course is taken live or recorded, and the improvement of the teaching program have little relationship with online course satisfaction.

In order to improve the satisfaction of online teaching, based on the above findings, the following suggestions are made: (1) in terms of school policy support, at least six aspects of implementation are needed: unified school deployment, provision of fine services, development of teaching implementation standards, development of teaching evaluation system, training, and implementation of teaching supervision, so that the school can improve the level of precise management while providing good services; (2) coursework In terms of teaching, teachers can improve the promotion and feedbacks of course assignments on teaching quality from the three aspects of pre-course pre-reading materials, online teaching accompanying quizzes, and post-course extension materials and assignments; (3) Need to further improve from the perspectives of advanced curriculum, teachers' teaching 
informatization level, teaching fun, teaching interaction, teachers' teaching skills, teaching style selection, and students' attendance rate, etc. teaching effectiveness; (4) the need to provide the necessary guarantee of online teaching platform and network environment from the perspectives of network quality, number of online courses, ease of operation, quality of service, functionality, platform operation performance, platform stability, etc.; (5) the need to further improve the quality of course resources from the dimensions of practicality, update speed, form, content, etc. The sudden outbreak of the new crown pneumonia in 2019 has kicked off the "online movement" in the history of domestic education, and many university teachers have started to have unprecedented remote online teaching experiences. In this study, we analyzed the influence of various factors on the online teaching satisfaction of college teachers during the Newcastle pneumonia epidemic, and drew conclusions. It should be noted that differences in sample backgrounds such as online teaching course type, discipline, and faculty gender may also be potential factors influencing the sample's attitude toward online teaching; the factor of faculty teaching style was only considered in three question items, and collecting more samples and conducting a more comprehensive analysis will be the research to be launched later.

\section{REFERENCES}

[1] Guidance on the organization and management of online teaching in general higher education institutions during the period of epidemic prevention and control from the Office of the Leading Group for Responding to the Novel Coronavirus Infection Pneumonia Outbreak, Ministry of Education [EB/OL]. http://www.moe.gov.cn/srcsite/A08/s7056/202002/t202 00205_418138.html.s

[2] Shen Zhen. Online teaching strategies of ideological and political theory courses in colleges and universities under epidemic prevention and control[J]. Journal of Ideological and Theoretical Education, 2020, 3: 15-19.

[3] Yuan Bo, Song Li, Peng Song. Exploring the online teaching of graduate students in live mode[J]. Modern Educational Technology, 2020,(30): 114-119.
[4] Dai Q, Shen H, Wang L. The Pedagogical Reform of "Packaging Chromatic Science " with the Internet Plus Strategy[C]// Proceedings of the 2nd International Seminar on Education Research and Social Science (ISERSS 2019). 2019.

[5] Wang YQ, Zhang YY, Zhou YL, et al. Application of online teaching methods in teaching pediatric clinical practice during the novel coronavirus pneumonia epidemic[J]. Chinese Journal of Medical Education,2020, (40): 500-503.

[6] Shen Zhen. Online teaching strategies of ideological and political theory courses in universities under epidemic prevention and control[J]. Journal of Ideological and Theoretical Education,2020, (3): 15-19.

[7] Yang YJ, Wang J, Yan Y, et al. Investigation and analysis of online teaching during the prevention and control of novel coronavirus pneumonia epidemic[J]. Teaching Research,2020,(10): 19-23.

[8] Meng A-Q, Li X-L, Wu S-S. A survey and analysis of college students' online learning psychological situation during the new coronavirus pneumonia epidemic[J]. Journal of Dezhou College, 2020, 36(2): 14.

[9] Yang Yi, Su Ping, Song Jiayi, et al. Online teaching practice based on enterprise WeChat platform and online education integrated platform $[\mathrm{J}]$. University Chemistry, 2020:1-1.

[10] Zhu Hongbing. Questionnaire survey and statistical analysis methods [M]. Beijing: Electronic Industry Press, 2019:37-38.

[11] Xue Wei. SPSS statistical analysis methods and applications [M]. Beijing: Electronic Industry Publishing House, 2017:172-177. 